\title{
Postural studies in pulsatile ocular blood flow: I. Ocular hypertension and normotension
}

\author{
D R Trew, S E Smith
}

\begin{abstract}
Measurements of pulsatile ocular blood flow (POBF) have been recorded in a group of healthy, ocular normotensive volunteers and ocular hypertensive patients recruited from outpatients. Use of a pneumotonometric probe linked to a Langham ocular blood flow system enabled readings of intraocular pressure and its variation with heart rate (ocular pulse) to be taken in erect and supine positions. Pulsatile ocular blood flow was calculated from these values by means of the pressure-volume relationship previously described for living human eyes. Assumption of the supine posture was accompanied by a significant rise in intraocular pressure; in normal eyes (mean, with SEM) (3.1 (0.4) $\mathrm{mmHg}, p<0.0001)$ and to a greater extent in ocular hypertensive eyes (4.7 (0.6) $\mathrm{mmHg}, p<0.0001$ ). The POBF did not differ significantly between normotensive and ocular hypertensive groups in either the erect or supine postures. In both groups, however, assumption of the supine posture was accompanied by a significant fall in POBF (normals: -121 (21) $\mu / / \mathrm{min}, \mathrm{p}<0.0001$; ocular hypertensives: $-75(16) \mu \mathrm{l} / \mathrm{min}, \mathrm{p}<0.0002)$. These reductions in POBF represent decrements of $27.5(3.0) \%$ and $17.1(3.8) \%$ respectively. Pulsatile ocular blood flow is reduced in the supine posture, and this may result in tissue hypoxia in subjects at risk of developing glaucoma. A companion paper describes the measurement of POBF in a group of patients with chronic open angle glaucoma treated with topical timolol $\mathbf{0 \cdot 2 5 \%}$.
\end{abstract}

A rise in intraocular pressure (IOP) on lying down is a well described phenomenon and has been confirmed by means of several different techniques. It occurs in both healthy subjects ${ }^{1-4}$ and to a greater extent in ocular hypertensives. ${ }^{5}$ The apparent ability of many eyes to withstand raised pressures without developing glaucomatous changes has caused much speculation. Comment has often centred on the protective role of the ocular blood supply, particularly to the optic nerve head, in the hypertensive group. . $^{6-8}$

An adequate blood flow to this region is essential in maintaining normal visual function, but both experimentally and clinically rates of flow have always been difficult to measure owing to the inaccessibility of the posterior ciliary arteries. In recent years a number of experimental techniques have been used to measure regional flow rates, particularly radiolabelled microspheres ${ }^{79}$ and more recently, and indirectly, by 2-deoxyglucose uptake ${ }^{10}$ and iodoantipyrine clearance. ${ }^{6}$ There are obvious limitations to these methods in that investigation is confined to animals which must be killed for the eyes to be assessed in the laboratory and results obtained. There has also been renewed interest in the use of indocyanine green dye angiograms attempting to characterise pulsatile choroidal blood flow."

Established techniques in human subjects have concentrated on a number of clinical applications. Laser Doppler velocimetry has been used to measure retinal flow, ${ }^{1213}$ and attempts have also been made to assess optic nerve head blood velocity, ${ }^{14}$ but the depth of measurement is difficult to clarify and may represent only superficial retinal flow. Photographic and fluorescein angiographic methods have also been used to measure mean retinal circulation time, ${ }^{15-17}$ and videoangiography promises useful information for the future. ${ }^{18}$.

However, the retinal circulation contributes only $5 \%$ approximately of the total ocular circulation $^{131920}$ and does not supply the optic nerve head, which is served essentially by the posterior ciliary circulation. ${ }^{21}$ The ability to measure total ocular flow incorporating the ciliary supply, which must be its major component, may therefore give a better understanding of the haemodynamics of this critical region.

Use of a pneumotonometric probe linked to a Langham ocular blood flow system permits the calculation of the pulsatile component of ocular blood flow. The values are derived from an analysis of the IOP pulse waveform, the heart rate, and the amplitude between systolic and diastolic intraocular pressures (the ocular pulse), factors which are discussed later in the paper.

This study has been undertaken to record derived values of $P O B F$ in healthy ocular normotensive and hypertensive subjects and to measure any changes related to posture.

\section{Subjects and methods}

\section{SUBJECTS}

Eighteen healthy ocular hypertensive $(\mathrm{OH})$ patients were recruited from outpatients. Ocular 
Table 1 Postural changes in ocular and systemic variables concerned in pulsatile ocular blood flow in healthy ocular normotensive and hypertensive subjects: mean (SEM)

\begin{tabular}{|c|c|c|c|c|c|c|c|c|}
\hline \multirow{2}{*}{ Variable } & \multirow[b]{2}{*}{ Erect } & \multicolumn{3}{|c|}{ Normotensives } & \multirow[b]{2}{*}{ Erect } & \multicolumn{3}{|c|}{ Hypertensives } \\
\hline & & Supine & Difference & $p$ & & Supine & Difference & $p$ \\
\hline $\begin{array}{l}\text { Heart rate }(\mathrm{bpm}) \\
\text { Mean BP }(\mathrm{mmHg}) \\
\text { IOP }(\mathrm{mmHg}) \\
\text { Pulse amplitude }(\mathrm{mmHg}) \\
\text { POBF }(\mu \mathrm{l} / \mathrm{min})\end{array}$ & $\begin{array}{c}70(1 \cdot 5) \\
97 \cdot 4(2 \cdot 6) \\
16 \cdot 2(0 \cdot 7) \\
1 \cdot 8(0 \cdot 2) \\
453(46)\end{array}$ & $\begin{array}{c}59(1 \cdot 5) \\
90 \cdot 8(2 \cdot 9) \\
19 \cdot 3(0 \cdot 7) \\
1 \cdot 8(0 \cdot 2) \\
332(40)\end{array}$ & $\begin{array}{l}-11(1 \cdot 6) \\
-6 \cdot 6(2 \cdot 0) \\
+3 \cdot 1(0 \cdot 4) \\
0 \\
-121(21)\end{array}$ & $\begin{array}{l}<0.0001 \\
<0.004 \\
<0.0001 \\
\text { NS } \\
<0.0001\end{array}$ & $\begin{array}{c}81(3 \cdot 5) \\
104 \cdot 9(2 \cdot 7) \\
22 \cdot 6(0 \cdot 7) \\
2 \cdot 1(0 \cdot 1) \\
427(26)\end{array}$ & $\begin{array}{l}65(3 \cdot 0) \\
98 \cdot 1(2 \cdot 1) \\
27 \cdot 3(0 \cdot 7) \\
2 \cdot 4(0 \cdot 2) \\
352(26)\end{array}$ & $\begin{array}{l}-16(1 \cdot 9) \\
-6 \cdot 8(2 \cdot 0) \\
+4 \cdot 7(0 \cdot 6) \\
+0 \cdot 3(0 \cdot 1) \\
-75(16)\end{array}$ & $\begin{array}{l}<0.0001 \\
<0.005 \\
<0.0001 \\
<0.05 \\
<0.0002\end{array}$ \\
\hline
\end{tabular}

NS= not significant.

hypertension was defined as a Goldmann intraocular pressure of $22 \mathrm{mmHg}$ or more when seated, on at least three occasions in the clinic. There were 10 males and eight females with a mean age of $63 \cdot 1$ years (range 26-78). Twenty healthy volunteers (five males, 15 females) with a mean age of 50.4 years (range 26-65), who had normal ocular tension (NT), entered the study. There were no diabetics or systemic hypertensives in either group, and no subject was receiving medication, topical or systemic. Each gave written consent to participation, and the study was approved by the Ethics Committee of West Lambeth Health Authority.

\section{METHODS}

Recordings were made in duplicate with the subject standing and, after 15 minutes' rest, supine. Measurements of intraocular pressure and ocular pulse amplitude were obtained by pneumotonometry, performed after instillation of $0.4 \%$ benoxinate, linked to a Langham ocular blood flow system. ${ }^{22}$ Simultaneous recordings were made of heart rate by standard electrocardiogram (ECG) and mean systemic blood pressure (diastolic plus one-third of the pulse pressure) with a Takeda Medical UA-751 digital blood pressure meter.

\section{STATISTICAL ANALYSIS}

Comparisons between the two groups were made by the unpaired Student's $t$ test for the following variables: pulsatile ocular blood flow, intraocular pressure, ocular pulse amplitude, heart rate, and mean blood pressure. Within-group comparisons were made for these variables in the erect and supine postures by the paired $t$ test.

\section{Results}

No significant differences existed between values for the right and left eyes, so for clarity of

Table 2 Differences between ocular normotensive and hypertensive subjects in ocular and systemic variables concerned in pulsatile ocular blood flow: mean (SEM)

\begin{tabular}{llllll}
\hline Variable & Posture & $\begin{array}{l}\text { Normotensives } \\
(N)\end{array}$ & $\begin{array}{l}\text { Hypertensives } \\
(H)\end{array}$ & $\begin{array}{l}\text { Mean difference } \\
(H-N)\end{array}$ & $p$ \\
\hline Heart rate & Erect & $70(1 \cdot 5)$ & $81(3 \cdot 5)$ & +11 & $<0 \cdot 05$ \\
(bpm) & Supine & $59(1 \cdot 5)$ & $65(3 \cdot 0)$ & +6 & NS \\
Mean BP & Erect & $97 \cdot 4(2 \cdot 6)$ & $104 \cdot 9(2 \cdot 7)$ & $+7 \cdot 5$ & NS \\
(mmHg) & Supine & $90 \cdot 8(2 \cdot 9)$ & $98 \cdot 1(2 \cdot 1)$ & $+7 \cdot 3$ & NS \\
IOP $(\mathrm{mmHg})$ & Erect & $16 \cdot 2(0 \cdot 7)$ & $22 \cdot 6(0 \cdot 6)$ & $+6 \cdot 4$ & $<0 \cdot 0001$ \\
& Supine & $19 \cdot 3(0 \cdot 7)$ & $27 \cdot 3(0 \cdot 7)$ & $+8 \cdot 0$ & $<0 \cdot 0001$ \\
Pulse amplitude & Erect & $1 \cdot 8(0 \cdot 2)$ & $2 \cdot 1(0 \cdot 1)$ & $+0 \cdot 3$ & NS \\
$(\mathrm{mmHg})$ & Supine & $1 \cdot 8(0 \cdot 2)$ & $2 \cdot 4(0 \cdot 2)$ & $+0 \cdot 6$ & $<0 \cdot 05$ \\
POBF $(\mu \mathrm{l} / \mathrm{min})$ & Erect & $453(46)$ & $427(26)$ & -26 & NS \\
& Supine & $332(40)$ & $352(26)$ & +20 & NS \\
\hline
\end{tabular}

NS = not significant presentation tables and figures illustrate effects on the right eye only. The effects of postural changes on variables concerned with the calculation of pulsatile ocular blood flow are reported first. Values for both the normotensive and hypertensive groups are given (Table 1 mean, with SEM).

Both groups showed a significant rise in IOP on lying down, though this was greater in the hypertensives $(\mathrm{OH}: 4.7(0.6) \mathrm{mmHg}, \mathrm{p}<0.0001$; and NT: $3 \cdot 1(0.4) \mathrm{mm} \mathrm{Hg}, \mathrm{p}<0.0001)$. Ocular pulse amplitude (PA) increased on lying down in the $\mathrm{OH}$ group $(0.3(0.1) \mathrm{mmHg}, \mathrm{p}<0.05)$ but not in the normal controls. Pulsatile ocular blood flow (POBF) was significantly reduced in the supine position in both ocular normotensives $(\mathrm{NT}:-121$ (21) $\mu \mathrm{l} / \mathrm{min}, \mathrm{p}<0.0001)$ and hypertensives $(\mathrm{OH}$ : $-75(16) \mu \mathrm{l} / \mathrm{min}, \mathrm{p}<0.0002)$.

Mean heart rate was significantly reduced in the supine position in both groups $(\mathrm{OH}: 16(1.9)$ bpm, p<0.0001; and NT: $11(1.6)$ bpm, $\mathrm{p}<0.0001$ ). There was a significant fall in mean blood pressure in both groups on lying down (OH: 6.8 (2.0) mmHg, p<0.0005; and NT: 6.6 $(2 \cdot 0) \mathrm{mmHg}, \mathrm{p}<0.004)$.

\section{COMPARISON BETWEEN NORMOTENSIVE AND} HYPERTENSIVE SUBJECTS

Table 2 compares the values between the two groups for both erect and supine positions. The two groups showed marked differences in mean intraocular pressure (erect: $6.4 \mathrm{mmHg}$, $\mathrm{p}<0.0001$; and supine: $8.0 \mathrm{mmHg}, \mathrm{p}<0.0001$ ). While there were differences in POBF between the normotensives and hypertensives, the values did not reach statistical significance. Fig 1 illustrates the fall in POBF which occurs in both groups associated with the supine rise in IOP.

Ocular pulse amplitude was greater in the $\mathrm{OH}$ group than the normals in both erect and supine positions, though the difference reached statistical significance only in the latter $(p<0.05)$. These values are illustrated in Fig 2.

The ocular hypertensives had a higher mean heart rate than normals in both positions, but the difference was significant only when standing (erect: $11 \mathrm{bpm}, \mathrm{p}<0.05$; supine: $6 \mathrm{bpm}$, $\mathrm{p}=\mathrm{NS}$ ). Similarly, mean blood pressure was higher in the $\mathrm{OH}$ group, but the differences failed to reach statistical significance.

\section{Discussion}

The technique of pneumotonometry has been available for some considerable time and the accuracy of recorded IOP measurements compared with a Goldmann 'standard' has been 


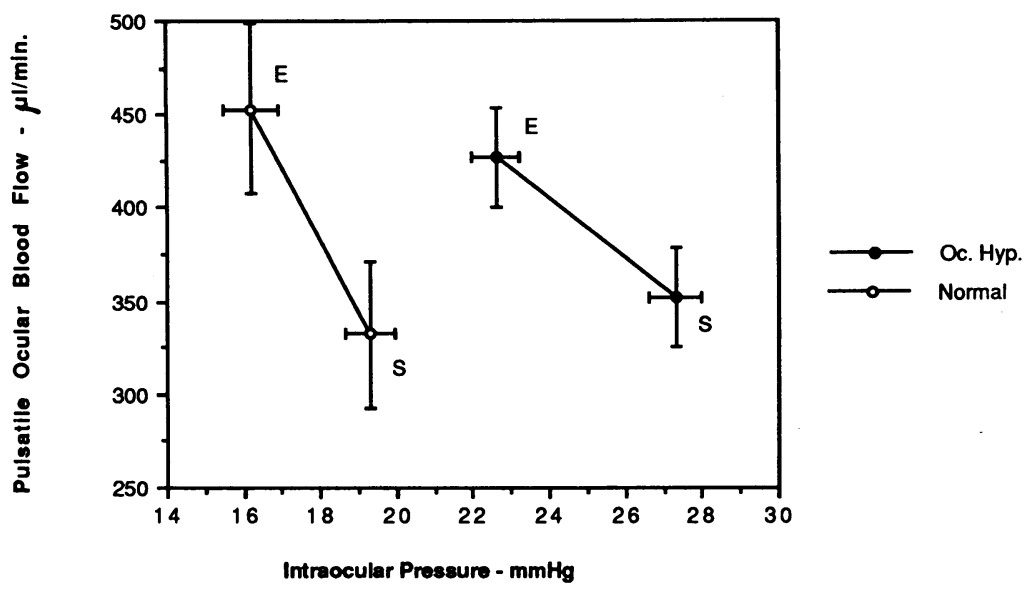

Figure 1: Relationship between mean intraocular pressure and pulsatile ocular blood flow in the right eye ( $n=20$ normals; 18 ocular hypertensives). Vertical and horizontal lines indicate SEM. $E=$ erect; $S=$ supine. established previously. ${ }^{23}$ Our version of the Langham system uses a compressed air cylinder to deliver a constant gas flow to the hand-held pneumotonometer probe. Measurements are easy to perform, and the computer records values every 30 milliseconds over a five-second time period.

The variation of the IOP with the heart rate is presented by the computer in waveform (Fig 3 ) and allows the calculation of the pulse amplitude between systolic and diastolic intraocular pressures (the ocular pulse). ${ }^{24}$ This pressure difference corresponds to an ocular volume change which occurs as a bolus of arterial blood enters the eye during systole. ${ }^{25}$ Manometric studies, both in enucleated eyes and in living human eyes prior to enucleation, have correlated the volume changes produced by a given bolus to a measured pressure increase. ${ }^{26}{ }^{27}$ At present it is unclear how the 'pressure-volume' relationship may be modified in eyes of different sizes. Recordings from myopic eyes tend to have a smaller pulse amplitude, and hypermetropic eyes the opposite. ${ }^{28}{ }^{29} \mathrm{We}$ are conducting a study to correlate pulse amplitude with axial length and refractive state of the eye.

The derived values obtained in this way are combined with two other parameters: first, the subject's heart rate and second, the duration of

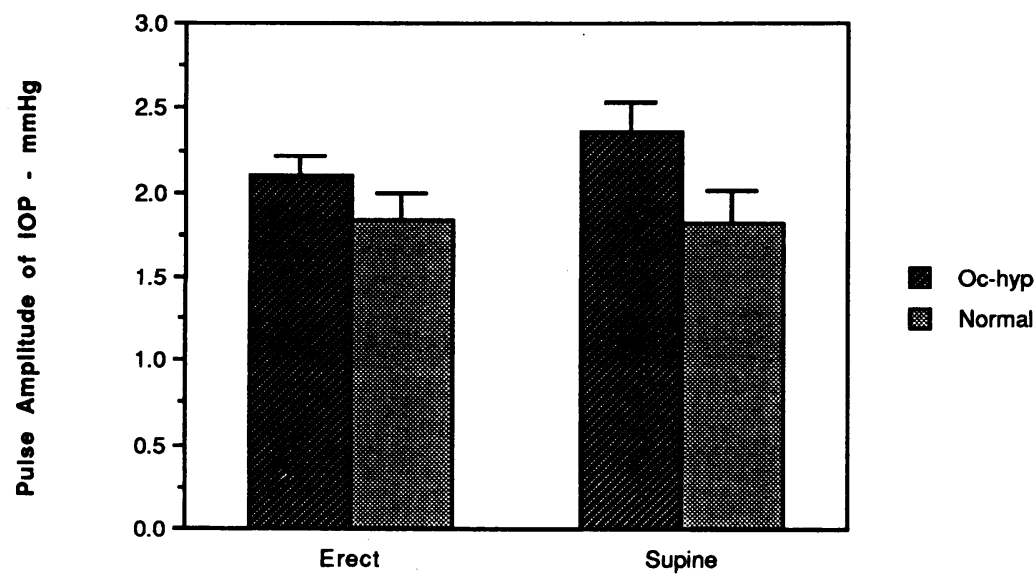

Posture

Figure 2: Postural changes in mean pulse amplitude of intraocular pressure. Vertical lines indicate SEM. the systolic and diastolic phases of the IOP pulse waveform. Calculation of the pulsatile component of ocular blood flow (POBF) is made from these data. ${ }^{22}$ It is emphasised that nonpulsatile flow is not measured by this technique, the calculations depending upon the IOP change produced by the entry of a bolus of arterial blood into the ocular circulation at systole. Doppler ultrasound studies of the ophthalmic artery have demonstrated a blood flow velocity during diastole, ${ }^{30}$ suggesting the existence of a nonpulsatile component to total ocular blood flow. Furthermore, these authors report an increased diastolic blood flow velocity in the supine position. The extent to which these changes affect non-pulsatile flow and therefore the total amount of blood passing through the eye remains unclear at present.

In our studies pulsatile ocular blood flow showed a marked fall in the supine position in both groups, and this corresponded with the rise in intraocular pressure associated with lying down. Furthermore, our values of POBF in normals, when supine, are somewhat lower than those described by Hopkin ${ }^{31}$ in a smaller number of normotensive subjects, but the mean IOP of our normotensive group was about $3 \mathrm{~mm} \mathrm{Hg}$ higher. No such association between POBF and IOP was found, however, when our two groups were compared. Although the ocular hypertensive group showed, as expected, higher mean pressures than normal, the pulsatile blood flow values were remarkably similar in the two groups, for both postures. This is an important observation as it implies that intraocular pressure is not the sole determinant of pulsatile ocular blood flow.

The pulse amplitude of IOP (the ocular pulse) is related to arterial pulsation and reflects the influx of blood into the eye with each heart beat; $;^{28}$ the greater the pulse amplitude, the larger the bolus of blood entering the eye. The ocular hypertensives showed a slightly greater pulse amplitude than did the normotensives, which was less stable with a change in posture. Although this has been noted before, our values for both groups are much lower than those found by Perkins in his series. ${ }^{29}$ As a group, the hypertensives were older, and an age related increase in scleral rigidity may well be expected to increase the pulse amplitude. However, in the same study Perkins found no correlation between age and pulse amplitude. Furthermore, another study by Friedman et al found that there were no significant age effects on the coefficient of scleral rigidity over the age of 60 , though its participants were somewhat older than our study groups. ${ }^{32}$

Mean blood pressure was higher in the ocular hypertensive group, in both positions. This may be of significance, as the perfusion pressure of the ocular vasculature is determined by the difference between mean ophthalmic arterial blood pressure and intraocular pressure; such postural changes in perfusion pressure have been recorded in other studies. ${ }^{334}$ In the presence of a raised intraocular pressure the arterial perfusion pressure (and therefore blood flow) may be maintained owing to an increase in mean blood pressure. Such an association may, however, be coincidental. Schulzer and Drance were unable 


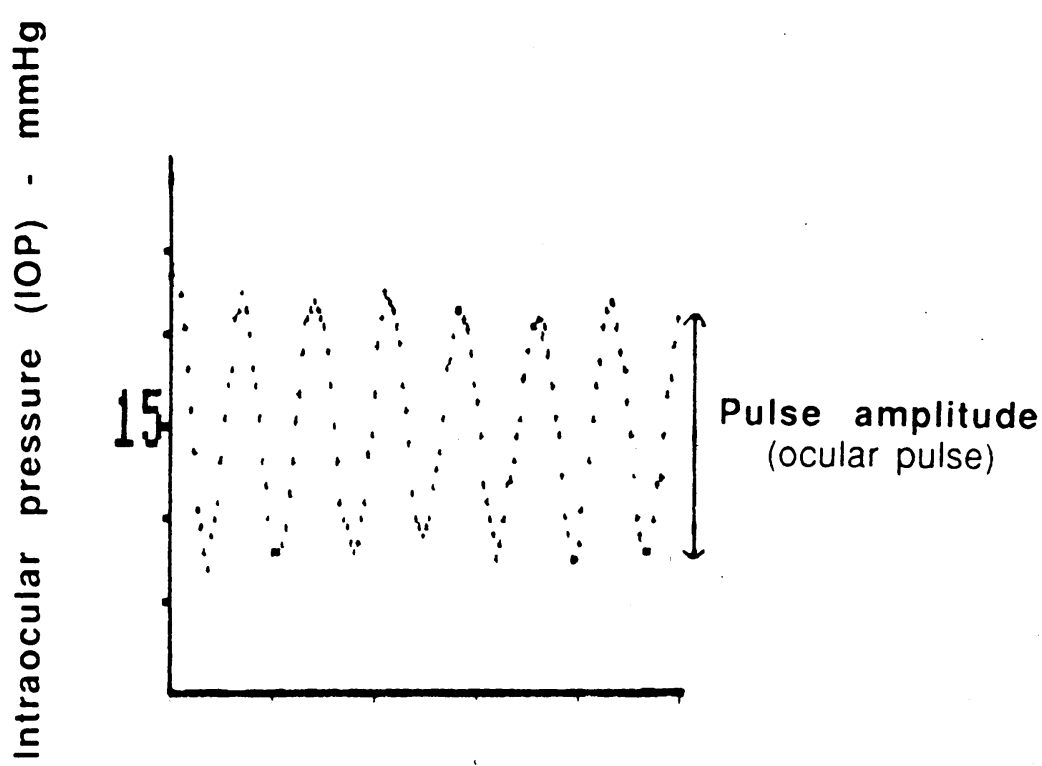

Time/s

Figure 3: Variation of intraocular pressure with time - the ocular pulse.

to find a positive correlation between IOP and systolic blood pressure in a large group of subjects..$^{35}$ They found that any associations were age related, which in our study could just reflect the differences between groups.

The resting heart rate falls profoundly when the subject is supine, and this affects POBF, which represents a volume flow per minute. A significant difference was noted between the two groups, but despite the ocular hypertensives displaying a higher mean heart rate, the POBF in the two groups was the same whether standing or lying. These observations of differences in heart rate are important, as they provide another possible reason for the postural reduction in POBF, but again they do not explain the similarities noted between the groups. An alternative explanation might be, of course, that the $\mathrm{OH}$ patients are maintaining their blood flow because of their higher heart rate and blood pressure, and this is further discussed below.

From our results it can be seen that differences exist in several parameters between the two groups. These combine, however, to produce pulsatile components of ocular blood flow which are the same in both ocular normotensives and hypertensives. Furthermore, both groups show a similar postural fall of POBF on lying down, but the reasons for these observations remain unclear at present. Additional information may be obtained, however, by performing a derived analysis of the volume of blood in a single arterial pulse. The heart rate exerts a major influence on POBF, and rate changes are presumably responsible, at least in part, for the postural alterations in flow observed here. Division of the POBF $(\mu \mathrm{l} / \mathrm{min})$ by the heart rate (beats $/ \mathrm{min}$ ) gives us a value for this single arterial pulse volume $(\mu \mathrm{l})$ which, interestingly, did not show a postural variation in the ocular hypertensive group (mean, SEM) (erect: 5.69 (0.35) $\mu \mathrm{l}$, supine: $5.61(0.4) \mu \mathrm{l})$. The normotensives did show a reduction in this value on lying down, although this was small (erect: $6.42(0.65) \mu \mathrm{l}$, supine: $5.58(0.6) \mu l \mathrm{p}<0.05)$. There was no significant difference between the groups.
Further investigation of the relative contribution of the heart rate to POBF and the possible determination of single arterial pulse volumes is clearly required. Investigations in this department are currently being performed on patients with cardiac pacemakers in which the heart rate can be set to a predetermined level, eliminating any postural variation and allowing closer scrutiny of POBF.

In conclusion, we have demonstrated a reduction in the pulsatile component of ocular blood flow, in both ocular normotensives and hypertensives, when they assume the supine posture from the upright. The mean values of POBF were similar in both groups despite the raised intraocular pressure of the hypertensives. A companion paper describes postural effects in a group of patients with chronic open angle glaucoma both with and without topical treatment.

We thank Mr M Falcon and Mr D Spalton for allowing us to study their patients and Karen Clark and Raymond Allen for their technical help.

The Langham OBF system was purchased with a generous rant kindly supplied by Dispersa (UK) Ltd.

DRT is supported by the Iris Fund for Prevention of Blindness DRT is supported by the Iris Fund for Prevention
and the Special Trustees of St Thomas's Hospital.

Financial support for the study was kindly provided by the
Find the Special Trustees of St Thomas's Hospital. Financial support for the study was
Royal National Institute for the Blind.

1 Anderson DR, Grant WM. The influence of position on IOP. Invest Ophthalmol Vis Sci 1973; 12: 204-12.

Galin MA, McIvor JW, Magruder GB. Influence of position on intraocular pressure. Am f Ophthalmol 1963; 55: 720-3.

3 Tarkkanen A, Leikola J. Postural variations of the intraocular pressure as measured with the Mackay-Marg tonometer. Acta Ophthalmol (kbh) 1967; 45: 569-74.

4 Tsukahara S, Sasaki T. Postural change in IOP in normal persons and in patients with primary wide open-angle and low-tension glaucoma. Br $\mathcal{X}$ Ophthalmol 1984; 68: 389-92.

5 Leonard TJK, Kerr Muir MG, Kirkby GR, Hitchings RA. Ocular hypertension and posture. Br f Ophthalmol 1983; 67: 362-6.

6 Sossi N, Anderson DR. Effect of elevated intraocular pressure on blood flow. Occurrence in cat optic nerve head studied with iodoantipyrine 1-125. Arch Ophthalmol 1983; 101: 98with 101 .

7 Alm A, Bill A. Ocular and optic nerve blood flow at normal and increased intraocular pressures in monkeys (Macaca irus): a study with radioactively labelled microspheres including flow determinations in brain and some other tissues. Exp Eye Res 1973; 15: 15-29.

8 Anderson DR. The posterior segment of glaucomatous eyes. Basic aspects of glaucoma research. Stuttgart: Schattauer, 1982: 167-90.

$9 \mathrm{Alm}$ A, Bill A. The oxygen supply to the retina, II. Effects of high intraocular pressure and of increased arterial carbon dioxide tension on uveal and retinal blood flow in cats. A study with radioactively labelled microspheres including study with radioactively labelled microspheres including Physiol Scand 1972; 84: 306-19.

10 Sperber GO, Bill A. Blood flow and glucose consumption in the optic nerve, retina and brain: effects of high intraocular pressure. Exp Eye Res 1985; 41: 639-53.

11 Flower RW, Klein GJ. Pulsatile flow in the choroidal circulation: a preliminary investigation. Eye 1990; 4: 310-8.

2 Hill DW, Pike ER, Gardner K. Laser Doppler velocimetry of the retinal blood flow. Trans Ophthalmol Soc UK 1981; 101: $152-5$.

13 Riva CE, Grunwald JE, Petrig BL, Sinclair SH. Blood velocity and volumetric flow rate in human retinal vessels. Invest Ophthalmol Vis Sci 1985; 26: 1124-32.

14 Riva CE, Grunwald JE, Sinclair SH. Laser Doppler measurement of relative blood velocity in the human optic nerve ment of relative blood velocity in the human

15 Hickam JB, Frayser R. A photographic method for measuring the mean retinal circulation time using fluorescein. Invest Ophthalmol Vis Sci 1965; 4: 1129-36.

16 Bulpitt C, Dollery CT. Estimation of retinal blood flow by measurement of the mean circulation time. Cardiovasc Res $1971 ; 5: 406-12$.

17 Nagasubramian S, Perkins ES, Gloster J. Combined reflectometric and photographic study of the retinal and choroidal circulation at raised intraocular pressure. Trans Ophthalmol Soc UK 1977; 97: 177-84.

18 Richard G. Differentiation of retinal circulation times by videoangiography. Ophthalmologica 1985; 191: 161-8.

19 Langham ME. Ocular blood flow and visual loss in glaucomatous eyes. In: Krieglstein GK, ed. Glaucoma update III. Berlin: Springer, 1987: 58-66.

20 Roy MS, Harrison KS, Harvey E, Mitchell T. Ocular blood flow in dogs using radiolabelled microspheres. Int $\mathcal{F}$ Radiat Appl Instrum (B) 1989; 16: 81-4. 
21 Henkind P, Hansen RI, Szalay J. Ocular circulation. In Duane TD, Jaegar EA, eds. Biomedical foundations of ophthalmology II. Philadelphia: Harper and Row, 1986: chapter 5: 1-54.

22 Langham ME, Farrell RA, O'Brien V, Silver DM, Schilder P. Blood flow in the human eye. Acta Ophthalmol (kbh) 1989; 191 (suppl): 9-13.

23 Quigley HA, Langham ME. Comparative intraocular pressure measurements with the pneumotonograph and Goldmann measurements with the pneumotonograph and

24 Silver DM, Farrell RA, Langham ME, O'Brien V, Schilder P. Estimation of pulsatile ocular blood flow from intraocular Estimation of pulsatile ocular blood flow from intraocular

25 Langham ME, To'mey KF. A clinical procedure for the measurements of the ocular pulse pressure relationship an the ophthalmic arterial pressure. Exp Eye Res 1978; 27 : 1725.

26 Eisenlohr JE, Langham ME, Maumenee AEW. Manometric studies of the pressure volume relationships in living and enucleated eyes of individual human subjects. $\mathrm{Br} \mathcal{F} O$ phthalmol 1962; 46: 536-48.
27 Langham ME, Eisenlohr JE. A manometric study of the rate of fall of the intraocular pressure in the living and dead eyes of human subjects. Invest Ophthalmol Vis Sci 1963; 2: 72-82.

28 Perkins ES. The ocular pulse and intraocular pressure as a screening test for carotid artery stenosis. $\mathrm{Br} \mathcal{F}$ Ophthalmo $1985 ; 69: 676-80$

29 Perkins ES. The ocular pulse. Curr Eye Res 1981; 1: 19-23.

30 Canning CR, Restori M. Doppler ultrasound studies of the ophthalmic artery. Eye 1988; 2: 92-5.

31 Hopkins SD. Ocular haemodynamics in cataractous eyes. Acta Ophthalmol (kbh) 1989; 191 (suppl) 43-8.

32 Friedman E, Ivry M, Ebert E, Glynn R, Gragoudas E, Seddon J. Increased scleral . rigidity and age-related macular J. Increased scleral rigidity and age-rel

33 Langham ME. Vascular pathophysiology of the ocular postural Langham ME. Vascular pathophysiology of the ocular post
response. Trans Ophthalmol Soc UK 1975; 95: 281-7.

34 Hague S, Hill DW. Postural changes in perfusion pressure and retinal arteriolar calibre. Br f Ophthalmol 1988; 72: 253-7.

35 Schulzer M, Drance SM. Intraocular pressure, systemic blood pressure, and age: a correlational study. $\mathrm{Br} \mathcal{F}$ Ophthalmol 1987; 71: 245-9.

\section{FIFTY YEARS AGO}

\section{Eye Injuries in Air Raids}

Ophthalmology has been called the Cinderella of Medicine and Surgery, left alone to fend for herself, often with meagre accommodation and equipment, in a general hospital. On December 29 [1940], the night of the severest incendiary raid on London to date, Cinderella was much in evidence with the cinders and was very much occupied long after midnight. At one large eye hospital in the City, 280 corneal and conjunctival foreign bodies were removed from members of the Fire Services between midnight and 5.30 a.m. Charred material formed the bulk of these foreign bodies. Most of the men had been attended to at First Aid Posts by the instillation of castor oil drops, had returned to their duties, been compelled to retire again on account of discomfort and then visited an eye surgeon. The first 100 to be treated all removed their pad and bandage on leaving the hospital to return to their duties of fire-fighting and so for the remainder this therapeutic refinement was dispensed with, thus affording a saving of time and material. The eye injuries caused by flying glass have been severe and on one night at a general hospital in the City the eye surgeon operated from 8 p.m. to 5.30 a.m. There were three cases in which both eyes were penetrated by splinters of glass, the most tragic being a husband and wife. Eyes containing glass fragments shrink relatively quickly, save in a few exceptional cases where a glass fragment has been retained in the vitreous for years without complications.

It is difficult enough to persuade industrial workers to adopt devices for their ocular protection and likewise it seems that firemen and soldiers become irritated by any addition to their accoutrement and as the severity of their task increases they cast away all but what they consider essential, preferring to take risks. To those less actively engaged in air raid duties but whose presence is necessary in look-out posts and on patrols, a pair of glasses fitted with one of the kinds of safety glass would save a number of eyes from destruction. To those sheltering in houses the pasting of windows with net, their occlusion by wooden shutters and the advice to keep clear of windows should be of sufficient prophylactic value. Annotation in Br $\mathcal{F}$ Ophthalmol 1941; 25: 179-80. 